\title{
A Suburban Communications Network: Recurrence of Use, Growth of Participation, and the Challenges of Sustainability
}

\author{
Fiona Redhead
}

Margot Brereton
Queensland University of Technology, Australia

Corresponding Author.

f.redhead@,connect.qut.edu.au

Queensland University of Technology, Australia

m.brereton@qut.edu.au

This paper presents findings from a longitudinal research project exploring the use of a local digital community noticeboard and the mechanisms that have worked to grow and sustain community participation in this communications network.

The lessons learnt from this research include the importance of providing clear indication to community members that communications are being seen by the community, maintaining visibility of high interest communitybuilding communications, and involving community organisers. In discussion of our research, we suggest that future design supports visibility of long-term communications, and provides an accessible place to make communications public, with less emphasis on linking individual identities.

Keywords: Situated Display, Community Building, Local Communications, Longitudinal Study, Networked Noticeboard.

ACM Classification Keywords: H5.m. Information interfaces and presentation (e.g., HCI): Miscellaneous.

\section{Introduction}

This paper considers the problem of designing support for local community communications in a suburban community. Our interest in this problem emanated from our preliminary study

Redhead, F., Brereton, M. (2016). A suburban communications network: recurrence of use, growth of participation, and the challenges of sustainability. The Journal of Community Informatics, 12 (2), 179-201.

Date submitted: 2014-12-03. Date accepted: 2015-11-23.

Copyright (C), 2016 (the authors as stated). Licensed under the Creative Commons AttributionNonCommercial-ShareAlike 2.5. Available at: www.ci-journal.net/index.php/ciej/article/view/1182 
questioning how people communicate about local interests, which focused on the study of a local community association (Redhead \& Brereton, 2006). The findings of this preliminary research characterised the work of a local community association as private-strategic activity, where small groups of trusted people formed to share activity that was largely invisible to passive members and the broader community. In addition, the core of active members that carried out the bulk of association work did not significantly increase, despite significant growth in members. We found efforts to share and network communications, such as the association Web site, quickly become stagnant and out-dated as critical issues passed and community champions formerly active in the private-strategic activity burnt out and ceased to engage. At the beginning of the study there was little use of social media platforms. While email was used extensively within the association and other community groups to keep members updated, it was difficult for people to contact the broader community when relying on non-networked media such as hand delivered flyers, and heavily edited and costly local print media.

The observed problem from this preliminary research is the difficulty of motivating and sustaining wide community participation in local communications. With this problem as the focus of our work, we conducted a design investigation to explore ways of growing a networked local communications platform that relied less on the efforts of community champions to sustain community-building activity. We hypothesised that, with a good interaction design that removed some of the barriers to participation, we might be able to support greater reach to community members. The aim has been to build knowledge of the mechanisms that motivate community member participation in local communications and to understand the challenges of sustaining this participation.

When we refer to participation in this paper, we mean participation in making and responding to local communications, rather than taking a passive role in only receiving local communications. This research is focused on enabling wide community participation in making a local communications network, through accessible means that allow direct contribution.

This research has grown over time and has been grounded in the physical, social, and technical infrastructure of the community, including shopping centres, people's homes, schools, organisations, community Web sites, social media use, and use of individually owned technologies. Our methodological approach has been to observe the work of a local community as a whole largely through the lens of a local digital community noticeboard, rather than the work of only a few in the community, to discover interaction patterns that mesh with the day-to-day work of local community, rather than exceptional events, and to build a place that accommodates diverse and emerging interests, rather than defined interests of established groups. Observations have been made in the rhythms of daily routines and in a manner that is not isolated from occurrences that have impact on community infrastructure and practices.

The central prototype is a digital community noticeboard to which anyone can post. We define a digital community noticeboard as networked information and communication technologies for local community member access to share messages relevant to the locality of the noticeboard. The noticeboard is a multi-channel communications platform with a networked Situated Display, associated Web site with email integration, and connection to social media (e.g. Facebook, Twitter, Flickr). Situated Displays are defined as displays 
physically or (semi-) permanently attached at a specific location (Kray et al., 2006). Although some traditional community noticeboards may differ slightly (e.g. strong control from the person offering the noticeboard), the characteristic of a traditional local suburban community noticeboard is one of shared use and at-a-glance interaction. Our logic for using a noticeboard metaphor has been to convey the public and shared nature of the communications platform. In addition, we envisaged a noticeboard model would suggest to people to quickly glance over posts (as on a traditional noticeboard) and this could be useful for introducing community-building notices that are relevant to the long-term interests of the community.

In this paper, we report on the characteristics of participation in a multi-channel local communications platform for support of a diversity of discussion beyond the intensity of any particular local crisis, short-term goals, and the usual local champions that are most likely to participate in the broader community. The introductory sections describe related work, the methodological approach that we took to conduct the research, the community that the research was conducted in, and the digital community noticeboard functionality. The findings discuss the kinds of posts that people had interest in looking at and the mechanisms that motivated and enabled growth in participation in local communications. The final discussion is focused on the challenges of sustaining shared communications and suggests design considerations for future work.

\section{Related work}

\section{Designing Technologies for Local Community Participation}

Community Informatics (CI) has a theoretical and practical purpose to build communities, develop information, and provide access to technology (Stoecker, 2004). Projects typically use participatory methods to enable communities through learning, to foster grassroots engagement for effective use of technologies, and for sustainability of community building initiatives. A key question for Community Informatics is how to sustain grassroots participation for sustainability of community building projects. Otis and Johanson (2004) conclude their literature survey addressing community building and ICTs with, 'community sustainability needs to be grounded in grassroots engagement to meet the needs and aspirations of community members. Failing that, ICTs remain just hardware' (Otis \& Johanson, 2004, pg. 24). The Seattle Community Network (SCN) and the Blacksburg Electronic Village (BEV) were established in the 1990s to provide access to Internet technologies to support community networking (i.e. email, email distribution lists, Web publishing, and Web hosting). These projects remain active today and the importance of grassroots participation for their longevity has been well-documented (Carroll, 2005; Schuler, 2005).

Local community networks that are sustained beyond issues of crisis, the energy of particular community champions or short-term agendas are the exception. Our challenge has been to discover mechanisms that work to build a local communications platform at a hyper-local suburban scale (population of 9,305 in the most recent census data available from 2011) (Australian Bureau of Statistics, 2013) where there are less formal or established groups that work for the interests of the local community than at the scale of Seattle and Blacksburg (population of 608,660 and 42,620 respectively in the 2010 census) (Blacksburg Government, 
2012; Seattle Government, 2011). In addition, the locality of our research lacks traditional public spaces such as a library or public hall. These kinds of spaces are known community hubs for face-to-face interaction and have been shown to be important in the introductory phases of the SCN and BEV to invite use (Carroll, 2005; Schuler, 2005).

\section{Situated Displays for Local Community Participation}

Other research on Situated Displays in work, institutional, urban, and residential communities has examined the connection between interaction with Situated Displays and social behaviours in the immediate space surrounding the display (Brignull, Izadi, Fitzpatrick, Rogers, \& Rodden, 2004; Brynskov et al., 2009; Churchill \& Nelson, 2007; Churchill, Nelson, Denoue, Helfman, \& Murphy, 2004; Greenberg \& Rounding, 2001; Jacucci et al., 2010; Peltonen et al., 2008; Peltonen et al., 2007). This body of research points to the utility of communal spaces as social hubs for interaction with public displays, and the potential of urban displays and media facades to engage people in the content displayed.

There are several studies that have reported the potential of using Situated Displays as a focal point in local communities to gather content, interaction, and response to communications, however issues around growth and sustainability were not reported (Alt et al., 2011; Ananny, Strohecker, \& Biddick, 2004; Churchill \& Nelson, 2007; Farnham et al., 2009; Gaver, 2002; Leong \& Brynskov, 2009). One longer term study, the Wray Photo Display, observed local community photo sharing through a public display over a period of years with a focus on Participatory Design (Taylor et al., 2007). The Wray Photo Display research is associated with a particular group (the local Computer Club) in the community and the vast majority of posts were uploaded by the main contact person (a local technology enthusiast and community volunteer). The researchers note some concerns with the limitations of working with one community group and having a particular point of contact within that group (i.e. strong views, influence, and also a high level of computer skills that may not be typical of other community members). However they also point to the advantages of having a point of contact or a 'human access point' to the broader community (i.e. making contact, getting feedback, offering technical support).

The research reported in this paper addresses the challenge of building participation in local community communications without reliance on a particular group or community champion to sustain the communications and activity. In addition, this research has observed local communications across a range of local community communication channels and formats (i.e. the digital community noticeboard, social media, email, text and images).

\section{Methodological approach: embedded and iterative design}

While the founding philosophy of this research draws from participatory design, both learning from and ensuring agency for those who will use or be affected by the design intervention, traditional participatory methods such as group workshops and exercises have not been well suited to the suburban scale of our project. Our methods have relied more on building connections with the community through quick chats and longer conversations in face-to-face and online local activity, and uses an exploratory approach to gather broader and spontaneous community communications (Redhead \& Brereton, 2008). This embedded approach has allowed time to recognise the rhythms of local community life and for people to 
contribute within their own routines, rather than that of a research agenda (Redhead \& Brereton, 2012).

Cederman-Haysom and Brereton write, 'if any new form of interface or computational appliance is to fit "invisibly" into a work practice, it must fit with the work and rely upon the skill of the practitioner to adapt and appropriate it into their existing material environment and set of practices' (Cederman-Haysom \& Brereton, 2006). Our research approach has allowed us to learn about the practice of being involved in local communications over time, to observe across a collective of people (rather than only a determined section of the community), and to blend exploration of technologies in the existing fabric of local communications.

The problem of seeking to observe 'in the wild', across the diversity of everyday life is 'one of reconciling the fragments' (Crabtree et al., 2006) of ethnographic data produced in the use (and non-use) of a design intervention. We have gathered data through system logging, observation and interviews, and responded to these fragments of ethnographic data using Reflective Agile Iterative Design (RAID). RAID is a framework for evolving social software and is a cyclic process of design (planning and implementation), feedback (hunting and gathering), and reflection (digestion and response). The primary contributing framework of RAID is Action Research with secondary influence from agile development, iterative design, user-centred design, and exploratory enquiry (Heyer, 2008; Heyer \& Brereton, 2008; Heyer, Brereton, \& Viller, 2008).

The following sections describe our methods of collecting data through the noticeboard system (notices posted and noticeboard interaction), observing as participant observers, and interviewing community members.

\section{The Exploratory Prototype in a Community Hub}

The Moggill General Store hosted the digital community noticeboard from October 2007 to January 2010 when it closed due to a change in leaseholders, while the Web site remained in use (4.5 years of data reported in this paper to March 2012). We had observed that despite the general store being a commercial business, the precinct acted as a community hub and people used the general store and Moggill State School for both planned and casual social interaction and more structured meetings. The noticeboard display was placed in this community hub for passersby to use in their ordinary routines of dropping off and picking up children, shopping, and informal meetings.

The digital community noticeboard acted as an exploratory prototype to invite community members to be participants in the research and to inform design iterations for a local communications network. In this way, it plays a similar role to a technology probe (Hutchinson et al., 2003) as a participatory method for design partnerships, as a lens for observation and testing in a real-world setting, and for grounded design inspiration. However, the exploratory prototype in this case was more about growing a design idea through reflection and iteration, than creating inspiration for new forms of technologies.

The digital community noticeboard is a central design research artefact as described above and is not intended to be a highly subscribed or competitive with existing popular social networks. We did not focus on success or failure in relation to subscription and readership statistics. Our aim has been to consider both use and non-use through an iterative design process, and to build understanding of recurrence of use, mechanisms of growth of 
participation, and the challenges of sustainability of a local communications network (as reported in this paper).

The digital noticeboard has enabled us to gather information on the kinds of communications that people post to the noticeboard and have recurring interest in viewing, and the mechanisms that have enabled growth of participation in a local communications platform.

\section{Our Role as Participant Observers}

As researchers we have undertaken roles as Participant Observers (being actively involved in a community to gain knowledge and understanding). One of the authors lives in the locality and this has enabled us to be involved in local activities as a member of the community, and as a friend of the community. This has involved attending local meetings (e.g. fundraising organisation), chatting to people about involvement in local communications, making posts as a member of the local community, making posts to seed activity and interest and to test long-term use, and moderating noticeboard posts. In addition, in mid 2011 a local community member that was active in community groups and well connected with residents started work in a Participant Observer role to create a stronger connection between the research and the community. The aim has been to observe local communication needs and to solicit feedback about use that are perhaps unavailable through short-term workshops, formal interviews, or as external observers to the activity.

In our analysis of use, we exclude our posts, research colleagues, and family posts when referring to growth data (i.e. number of posts per month). This paper only reports growth of local community member participation in posting to the noticeboard. However we do report local community response to our posts and recurring interest in viewing our posts. We include our posts in analysis of recurring use as these were part of the body of communications available to local community members through using the digital community noticeboard.

\section{Open Interviews with Community Leaders}

People in leadership roles in community organisations and groups such as environmental, political, social, sporting, and religious groups have a need to keep members up to date and contact the broader community. Working with these people and recognizing them as drivers in the community communications is key to understanding participation as they have a great deal of expertise in the practice of working within local suburban communities. The leaders we have had contact with are extremely well connected with others in and around the community, have a great deal of history in the place, and a deep understanding of the locality. We made efforts to stay in touch with leaders beyond interview sessions to understand their work in the community over time. Often this has taken the form of email communications relating to use of the prototype.

\section{The Locality}

The area in which this research includes has grown to two neighbouring suburbs, Moggill and Bellbowrie (figure 1), although suburban borders defining users are fuzzy. Moggill and Bellbowrie are outer western dormitory suburbs, situated about 18 kilometres from the Brisbane Central Business District, with a high dependence on commuting to neighbouring 
areas for community facilities including secondary schooling, library services, health services, local government offices, early childhood care, and recreational facilities associated with larger shopping districts such as restaurants, cafes, and cinemas.

The population of Moggill and Bellbowrie is 9,305. Families (including couples without dependant children) account for $89 \%$ of households. Access to the Internet is high: $91 \%$ of occupied private dwellings in Moggill and Bellbowrie have access to the Internet (Australian Bureau of Statistics, 2013). The Moggill and Bellbowrie area is a mix of suburban lots and larger semi-rural lots including some small farms.

There have been several issues in recent years that have motivated the community to collectively act. Major issues have included a proposal for a major arterial road through the locality, dissent about the main shopping centre management, and major flooding that left many households in need of financial support to rebuild. Local people have worked together on these issues over the years in various manifestations of formal associations and other ad hoc groups. There is a keen general interest in working together on issues that have impact on the community.

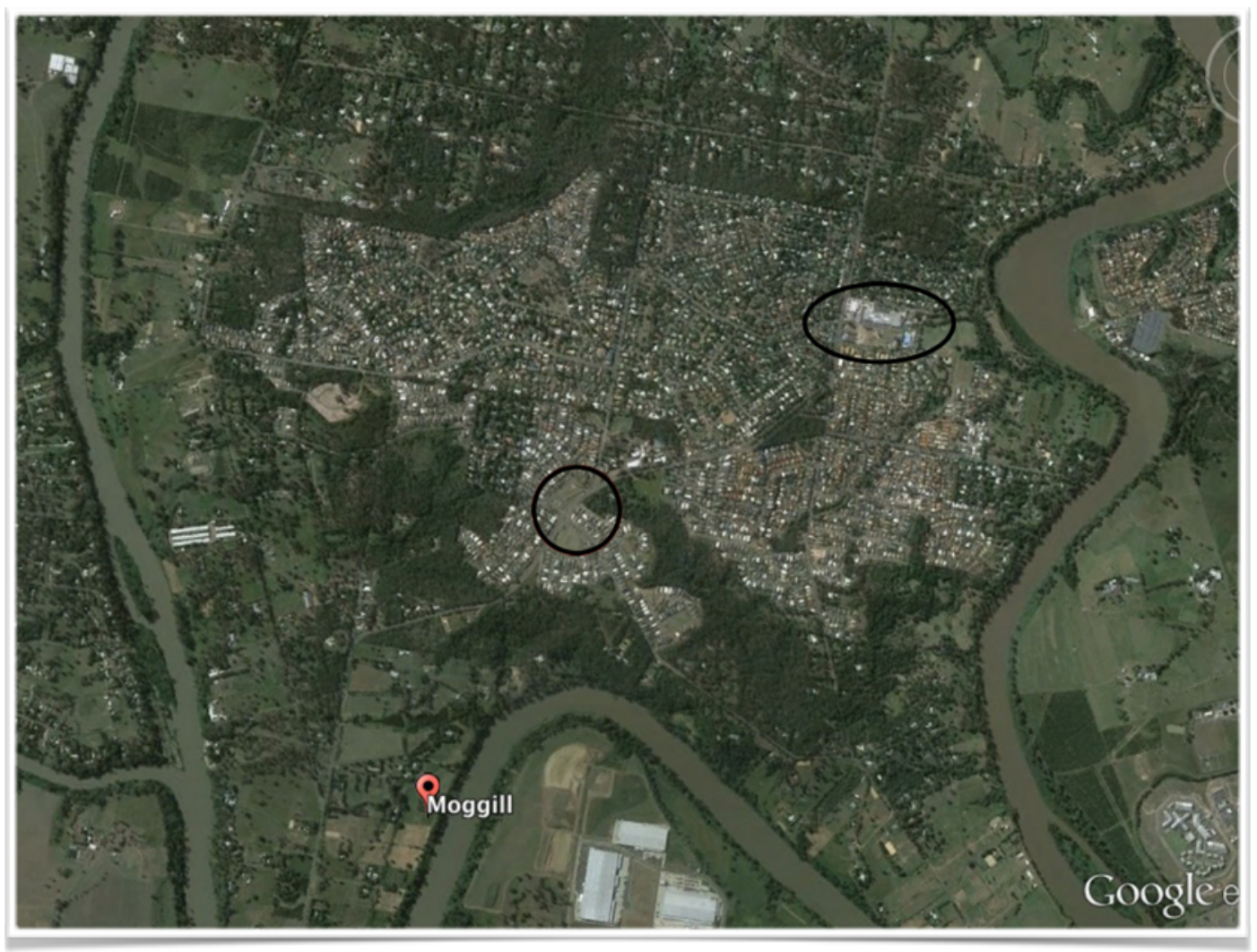

Figure 1: An aerial view of the locality with the larger Bellbowrie Shopping Centre to the top right, and the Moggill General Store further to the left.

\section{The noticeboard system}

The noticeboard is called Nnub (an abbreviation for neighbourhood nub) and has two main interfaces for interaction, a digital noticeboard display (figure 2) and a Web site with email and social media integration (figure 3). The noticeboard display is designed for quick interactions in the store where people can see the notices at a glance while passing by 
(Redhead \& Brereton, 2009). The display has a visual layout that is modelled on notices pinned to a physical noticeboard. People can browse posts by touching on the posts in view, or by touching the text navigation. In contrast, the Web site has a text-based layout with the latest notices listed in chronological order on the home page. The noticeboard display and Web site show identical content.

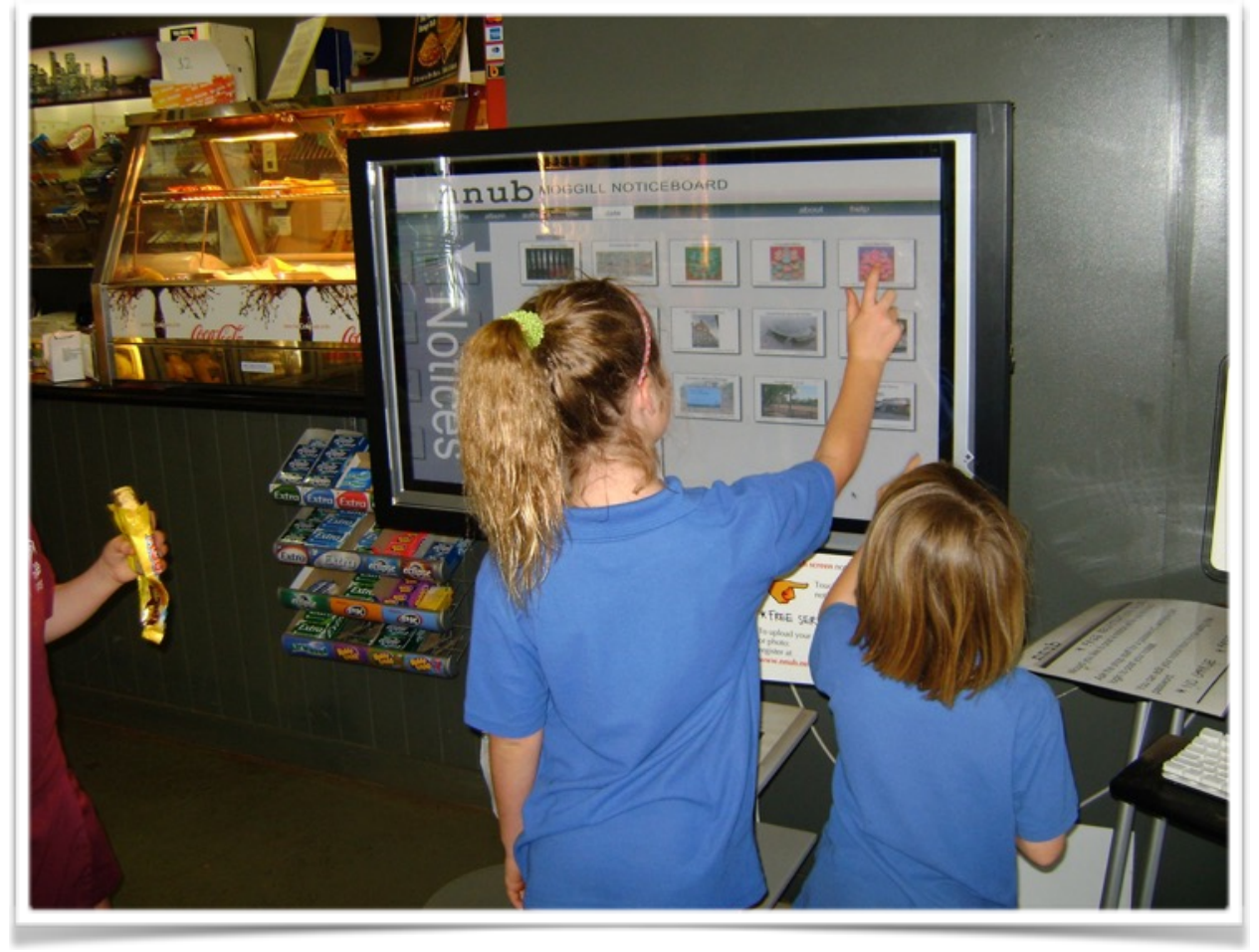

Figure 2: The display in use in the store.

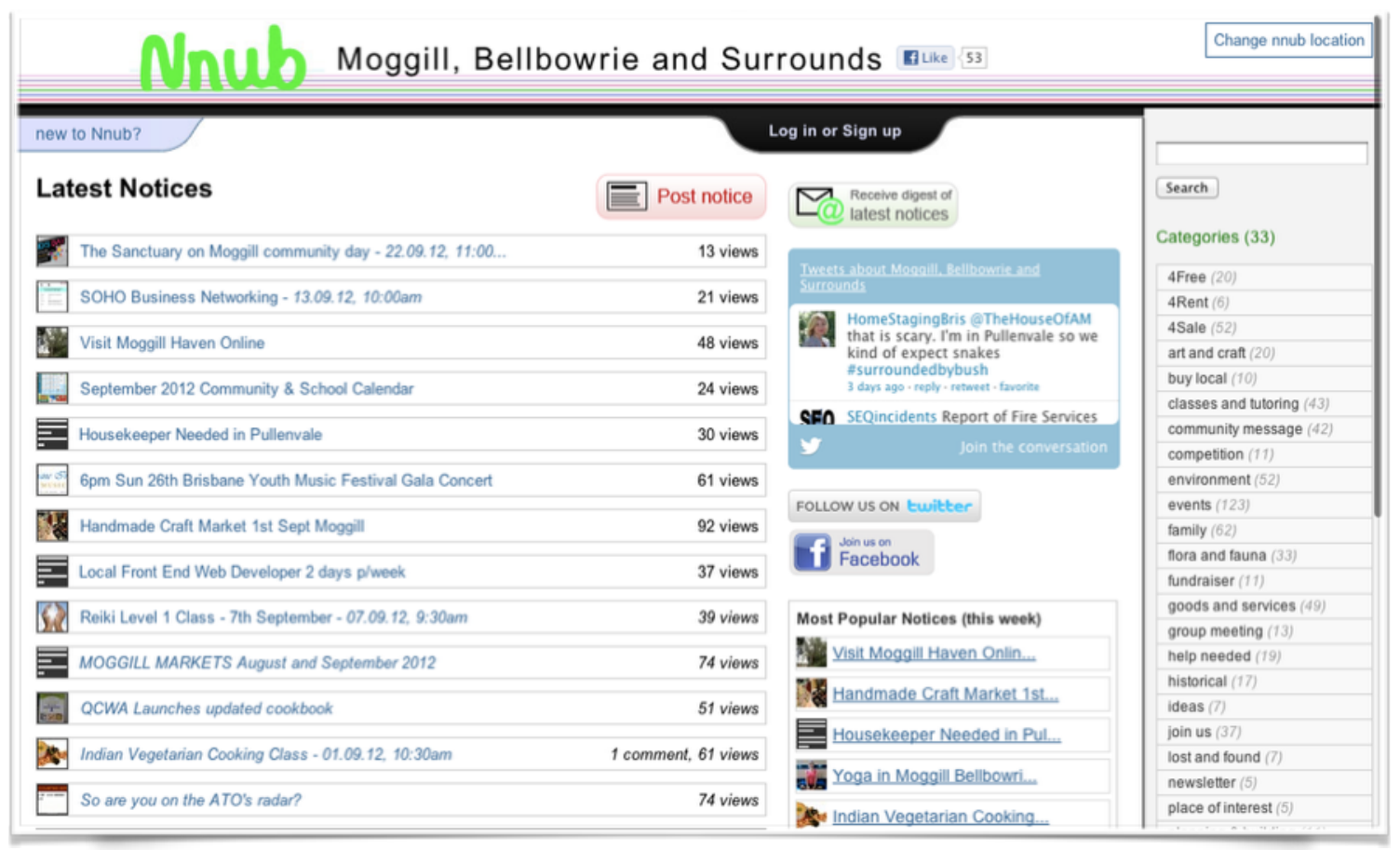

Figure 3: The display in use in the store. 
A post can be made to the noticeboard by registering with Nnub to submit a post through a Web form, emailing a post to the noticeboard, or drawing or writing a Scribble (Churchill \& Nelson, 2007) directly on the touch screen (on the noticeboard display). A post made through the Web site or by email can be text only, text and image(s), or image(s) only. Authors can edit, archive, and delete their posts. Registered users can submit comments to all notices (including Scribbles) using the Web site. All notices and comments are public and can be viewed without the need to $\log$ in.

The research team moderates both notices and comments for pornography and profanity, and other posts that are not directly relevant to the community (e.g. advertising spam) before being published.

A weekly email digest was introduced in March 2010 (after the store closed in January 2010). Email lists are used extensively by local community organisations to keep members informed (Redhead \& Brereton, 2006). Email provides a way for leaders to distribute updates quickly and cheaply to the bulk of their members, and as a way for members to feel connected to the groups they are interested in. With this in mind, we started to send an email digest as a means to give the digital community noticeboard presence in the community after the store closed and the noticeboard display was removed from the community hub. The digest is written by a research team member and includes an editorial to introduce links to the latest notices and highlight community activity for the week. Registered users can opt out of receiving the digest.

Nnub is linked to highly subscribed social media sites. Nnub directs all notices to Twitter feeds identified with the locality name of the Nnub (e.g. nnub_moggill) and displays Flickr feeds tagged with descriptors that are relevant to the Nnub locality (e.g. Moggill). A Facebook page and Facebook and Twitter widgets were also integrated with the Web site.

\section{Findings}

In this section we introduce general analysis of noticeboard use as background for more detailed analysis of the kinds of communications that have been of recurring interest to the local community, and mechanisms that have enabled growth and sustained use of the noticeboard as a local communications network. Following the main findings, the challenges of sustaining local communications networks are discussed.

Of the 256 registrations, 137 community members have contributed posts to the noticeboard. This is a significant number of distinct people posting to the noticeboard when considering that community organisations and groups often rely on a community champion or only a few committed people to keep communications active. The increase in the number of new visitor Web sessions per month has been consistent with the growth rate of registrations, and the growth in posts contributed by community members to the noticeboard (figure 4).

The noticeboard display and Web site have attracted different kinds of use. The noticeboard display has been used in an at-a-glance and in-the-moment manner. People browsed the noticeboard display at-a-glance and preferred to interact with images rather than text-based notices (text only or text with an image), and with the visual representations of the notices on the display rather than any text-based navigation. By contrast to use of the display at the store, we found the Web site has been used with more intentional purpose of posting and 
reading text-based notices. Text-based notices have been the most viewed posts on the Web site.

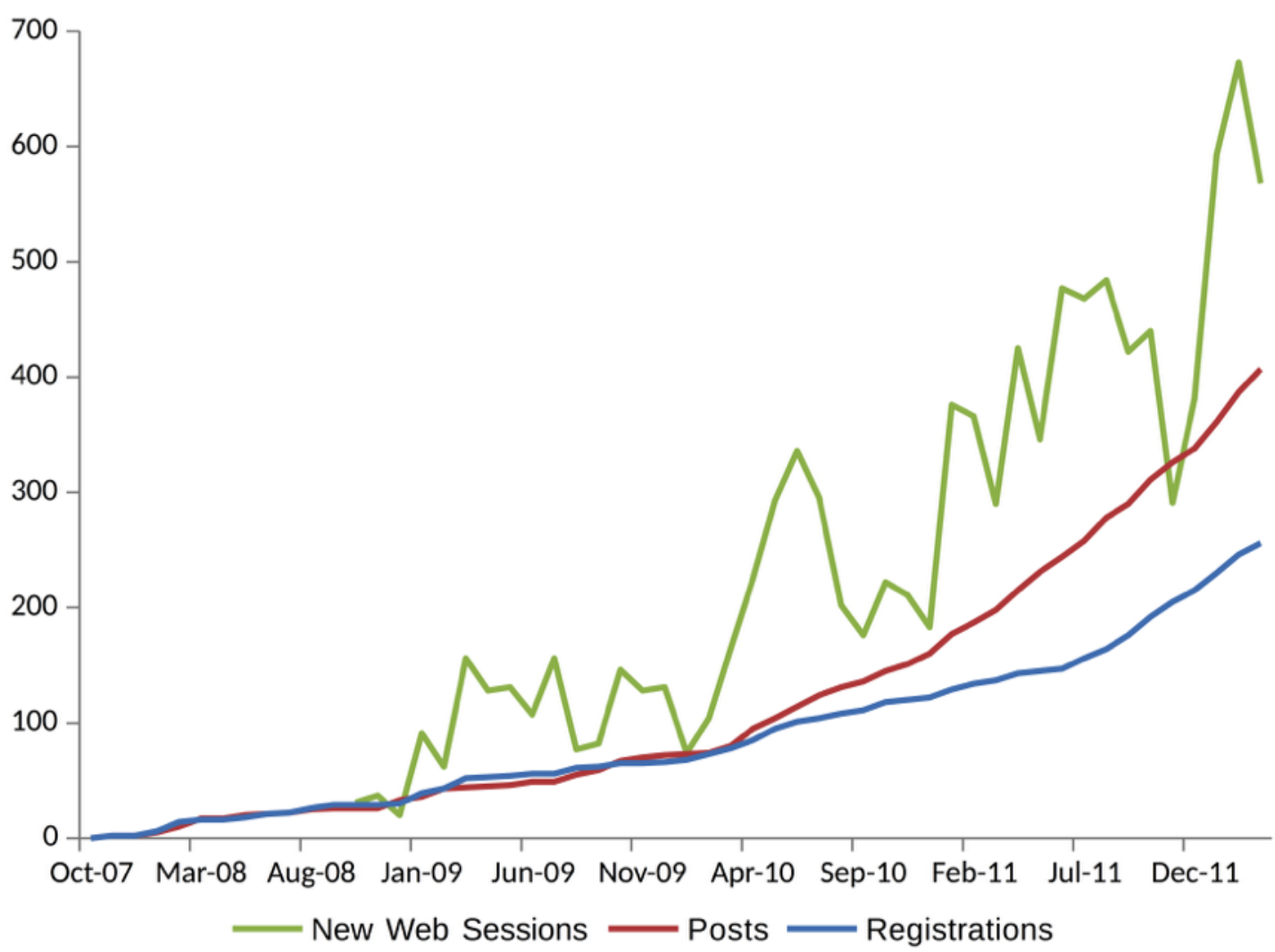

Figure 4: Number of new or unique Web sessions per month, growth of registrations and posts from community members (excluding posts from researchers and colleagues).

Text-based posts made to the noticeboard fall into two categories: community building or classifieds. We identify 'community-building posts' as those that aim to share local resources, and increase participation in local interests. We considered posts as community building if they:

- call for participation in either a discussion of local interest, or as a volunteer to help with a local activity,

- share information about local interests to keep the community informed (e.g. planning and development updates, wildlife in the area),

- share goods and services (e.g. offering free goods and services as opposed to selling them; support for local people in crisis),

- offer ongoing community activities at low cost as opposed to standard commercial rates (e.g. community exercise classes),

- present questions for information gathering (e.g. gather information about available land for community use or environmental concerns), or 
- gather interest in a new interest group (e.g. community garden).

In contrast, classifieds are more focused on broadcasting to the community. These posts are not trivial and do have a community-building aspect, however do not call for direct participation in the activity of community building. We consider posts as classifieds if they:

- advertise market price goods and services,

- inform about lost and found belongings, or

- advertise events (including fundraising events).

\section{Recurring Interest in Community-Building Communications}

By undertaking a long-term study it has been possible to observe communications that are beyond first or novel encounters and ephemeral interactions, and to identify communications that have been of recurring interest to the long-term interests of the community. While the noticeboard attracted people to view notices that featured images in the store, communitybuilding posts have been of the most interest to people over time on the Web site. The twenty most viewed notices over a two year and three month period (January 2010 to March 2012) were all community-building notices. Importantly these have been looked at, and in a few cases, commented on occasionally over years (figure 5). As this has occurred over years, these posts have not always had high visibility in the latest notices listing on the home page of the Web site, and would have required some searching to find them either through Web site navigation or through other search engines. This highlights the interest that the local community members had in community-building.

The most viewed notices mostly concern core community issues around community facilities and planning. These include information about a proposal for a new McDonald's franchise in the shopping centre, concerns over a monopoly of ownership of commercially zoned land in the locality and management of this commercial space, rebuilding of facilities after major city flooding (post office, swimming pool), a proposal to prevent recurring flooding, formal council neighbourhood planning, and possible land for community use. Other most viewed posts propose new or informal groups around an interest such as a gardening or handcrafts, show images of exceptional and novel events (particularly of the major flooding in January of 2011), and query an environmental concern (i.e. a strong and bad smell).

Nearly all of the most viewed posts begin with a short period of many views followed by a small number of views over a long period of time. As an exception, a post concerning a bad smell in the area (the post appearing in July 2010 and the largest bubble in figure 5) received many views in the first couple of days and only a few views following this. While this post concerns an issue at a moment in time and is likely to be of interest only in the short term, it does, by way of contrast, highlight the recurring interest in posts that address community issues that take time to consider and work through (e.g. planning and management of key facilities). 


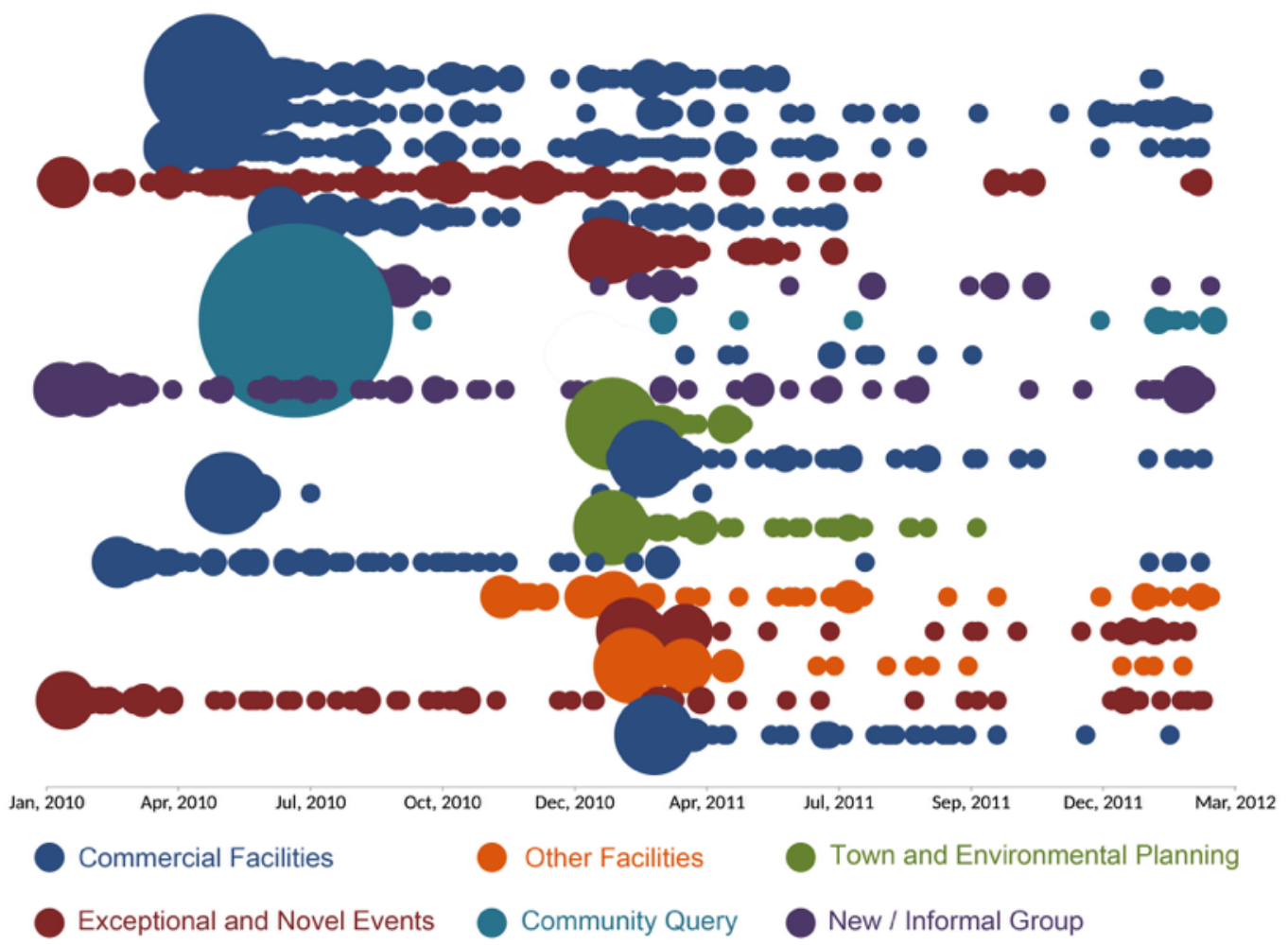

Figure 5: The twenty most viewed notices indicating daily frequency of views (by bubble size), and illustrating recurring interest in community-building posts over a period of years. The largest bubble indicates 99 views in a day.

\section{Trickled Passage of Community-Building Ideas Over Time}

We found new ideas trickle through the local communications fabric (e.g. various media, chats with friends, formal meetings) and often need a long time frame to be considered and realised by the community. To illustrate this kind of trickled passage, figure 6 shows views and comments on the Web site of an idea to start a community garden. The post proposed the use of funds from a stagnant community association, along with City Council grant funds to set up a community garden. Although the total number of views is not so large, this was one of the most revisited posts indicating that the idea of a community garden has been of recurring interest within the community over time.

Different communications channels are used for this trickled passage of ideas through the local communications fabric. While a community garden has not yet been created, further discussion of the idea has appeared over time in other local communications channels. Following a query about community gardening posted to a community Facebook group in February 2012 (by a different author to the post described above), a Facebook group was made to share gardening knowledge and ideas for setting up a produce garden and plant exchange. Around the same time a post calling for interest in creating a community edible garden was made to the noticeboard and has received a relatively high number of views indicating the continued interest in the idea.

In a similar manner, a post proposing a Men's Shed for the locality was made in mid 2010. A Men's Shed is open to men who would like to connect with other members of their community and offers a wide range of activities, including woodwork, bike repair, book club, 
computer use and discussion groups. While views of the post proposing the Men's Shed have been relatively high, the move from gathering interest in the idea to planning has happened over a period of years. To advance the idea, the proposal for a Men's Shed appeared in other communication channels including a community association Web site and Facebook group, an informal community Facebook group, the local government Web site, a local newspaper, and at public meetings.

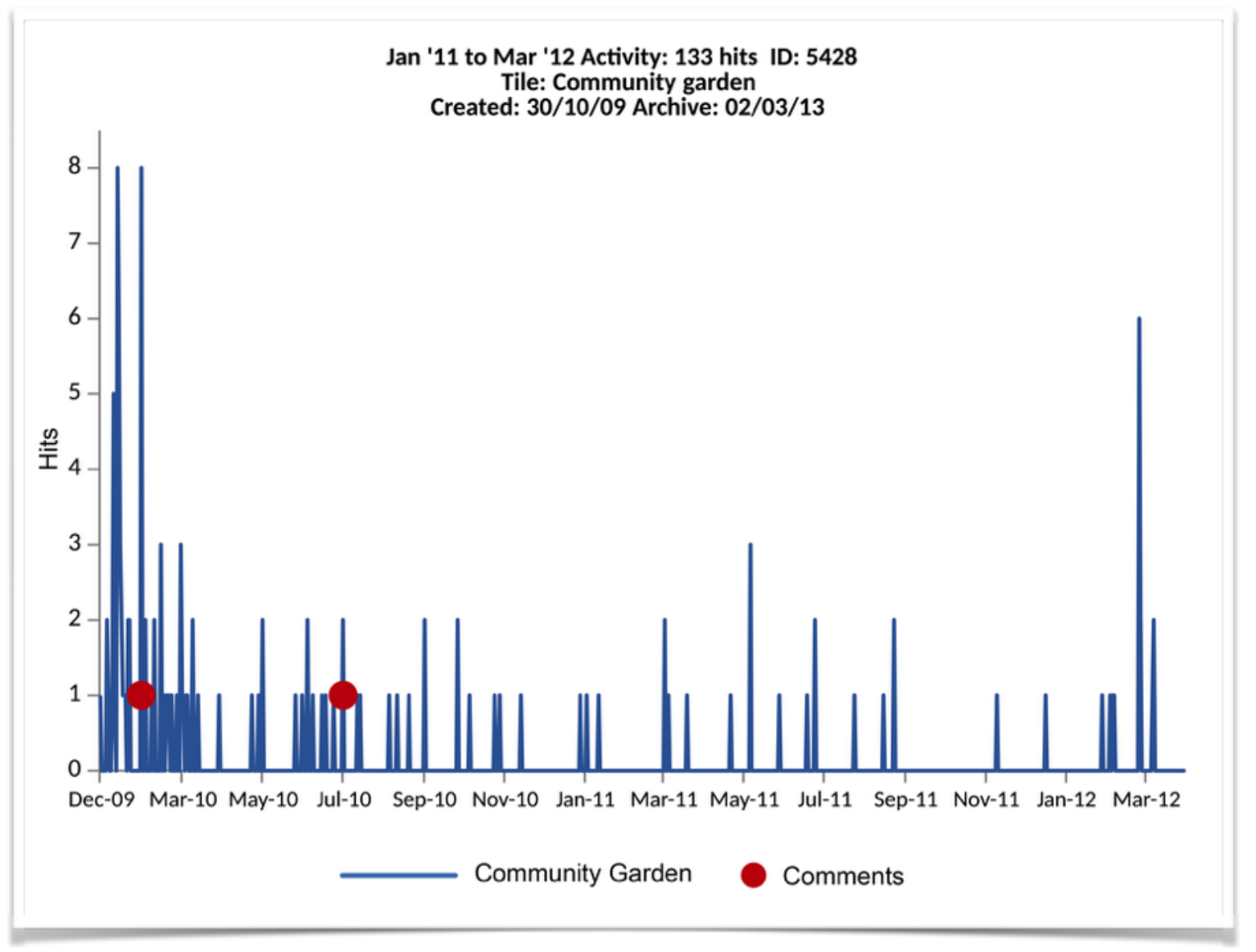

Figure 6: Views on the noticeboard Web site of 'Community garden'

We have found that people are interested in viewing, searching for, and discussing community-building posts and ideas over time. The lessons learnt about the recurring interest in local communications are:

- Community-building communications are looked at and searched for over a time frame of years.

- The time frame for realising and shaping local community building ideas is years.

\section{Mechanisms for Growth of Participation}

Initially interaction with the noticeboard display in the store was far greater than use of the Web site (Redhead \& Brereton, 2010). While this was promising in terms of attracting attention to community communications, growth of new registrations and posts was very slow. Images of exceptional and novel events were the most popular to view on the display (e.g. extreme weather conditions, visits from wildlife). Scribbles were used mostly by 
children to make quick and chatty kinds of posts that were meaningful only to the children that were involved in making the Scribble. While Scribbles greatly increased the number of posts contributed to the noticeboard, they were of little interest to the broader community likely because of their chatty and in-the-moment nature. Browsing in the store did not translate to in-home browsing (using the Web site) or to growth in registrations or posts.

Our role as facilitators in seeding use, the role of the email digest in growing contributions, and the role of community organisers in growing community building posts have been the main mechanisms for growing participation in local communications. These three motivators are discussed in the following sections.

\section{Our Role as Facilitators in Seeding Use}

Our role as Participant Observers facilitated early posts to the noticeboard. Most of this activity was to seed use, to explore the usefulness of the platform through making posts as Participant Observers, and to continually explore and debug the interface. While the number of posts made by community members slowly increased over the years, the number of posts made by researchers and colleagues was greater than the number made by community members for a period of three and a half years. However, we found noticeboard Web sites we had set up in other suburban localities at later stages in the development of the noticeboard system and with very little or no facilitation activity received negligible scattered posts over years. This highlights the role of facilitator as key to establishing early participation.

The rate of contributions from the community started to increase at a greater pace after the email digest was introduced (figure 7). Eventually the rate of posts from the community became greater than our facilitator posts (around July to August 2011) and building critical mass in community communications became less reliant on our role in seeding use.

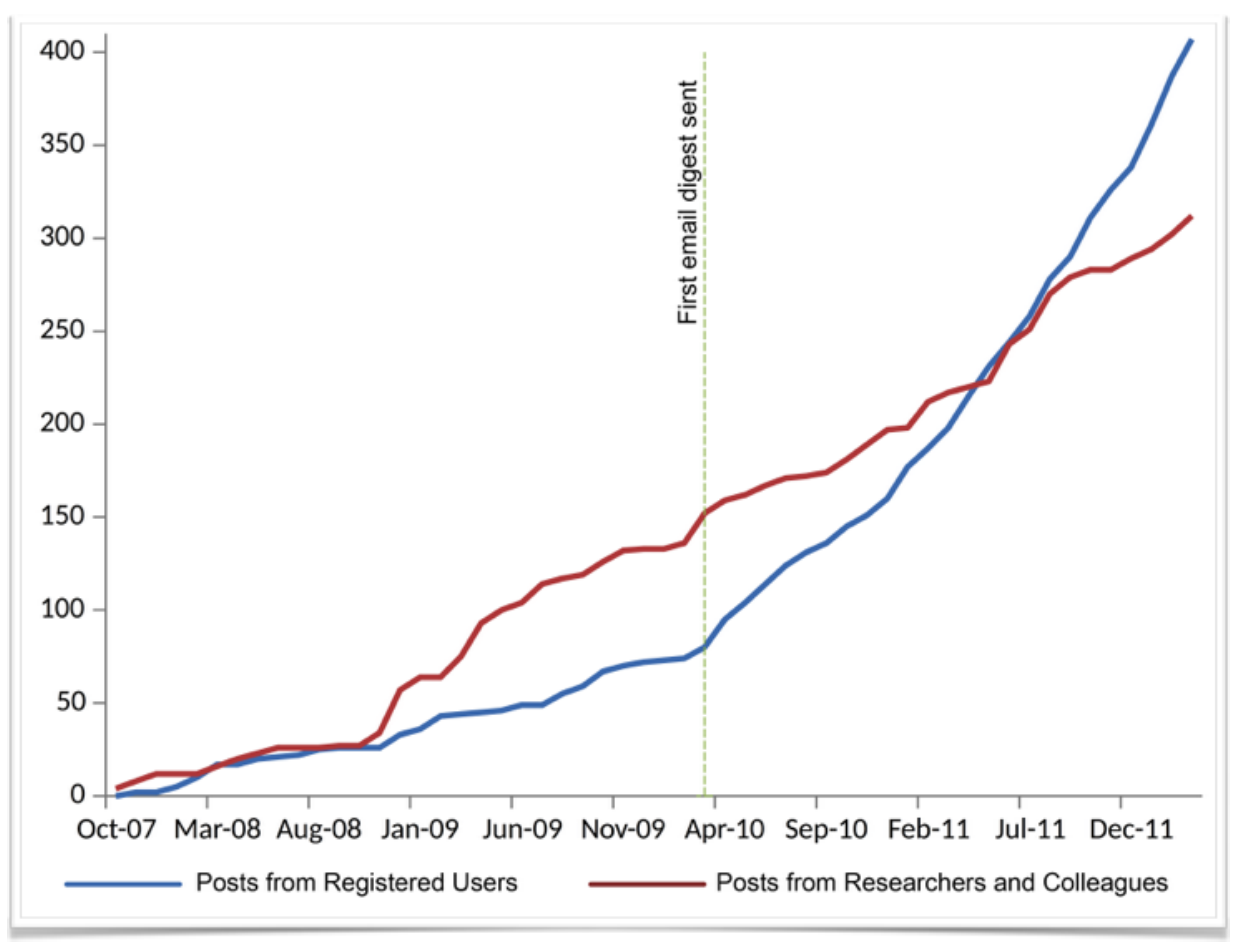

Figure 7: Registered user posts, and Participant

Observer and

Colleague posts. 


\section{The Role of the Email Digest in Growing Contributions}

An email digest sent weekly to registered users has increased the visibility of the posts and motivated an increased rate of contributions to the noticeboard (figure 8). Feedback received from users suggests the digest is perceived as a useful means for making communications distributed and visible, and for providing a sense of connection to the community,

I really appreciated also the e-mail that you wrote with each new batch of notices, as it gave my service double exposure-not to mention that I felt acknowledged for my work which gave my confidence a boost, thank you'.

The rate of posts from registered users increased from an average of 2.67 posts per month (or 0.62 posts per week) prior to the email digest, to an average of 13.63 posts per month (or 3.14 posts per week) after starting the email digest. Posts from researchers and colleagues remained relatively constant; an average of 5.07 posts per month (or 1.17 posts per week) prior to the email digest, to an average of 6.67 posts per month (or 1.54 posts per week) after starting the email digest.

The email digest has grown contributions by making communications visible in people's everyday routines of checking their emails and conveying usefulness as a channel that is known to be seen by all registered users.

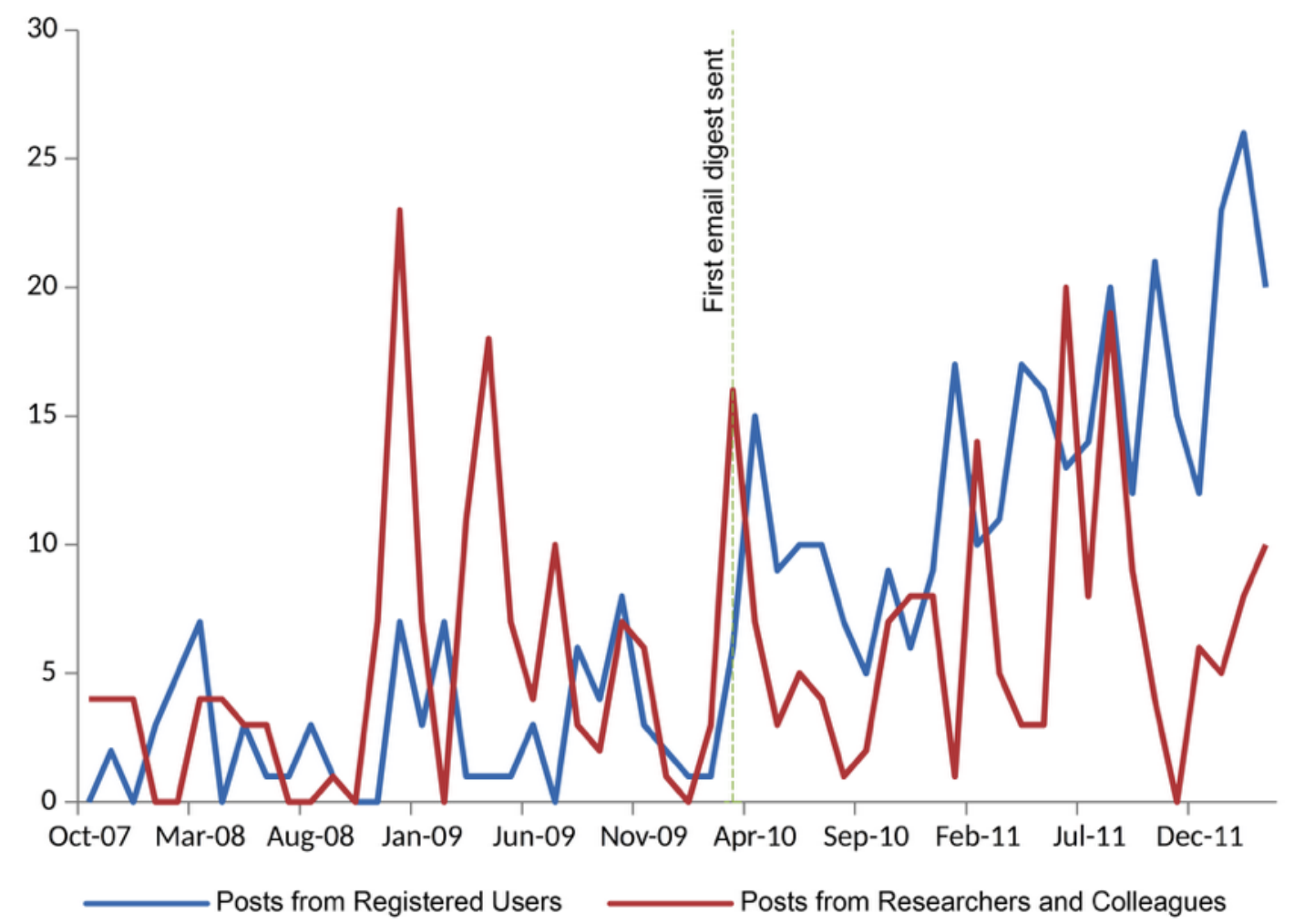

Figure 8: Number of posts made per month to the noticeboard 


\section{The Role of the Community Organisers in Broadening Participation}

The rate of posts from registered users increased after the email digest was introduced and this continued to increase over the following two years (figure 8). However, the email digest is only sent to registered users and this limited the reach of the digest to people already familiar with the noticeboard. As a result the rate of new registrations only slightly increased after the introduction of the digest. In June 2011, we introduced a local resident to our research team. She was an early adopter of the noticeboard and a well connected and active community organiser. This greatly increased the rate of registrations and we can identify one third of registrations (after June 2011) as being influenced by her quickly becoming acquainted with many groups and people in the community (figure 9).

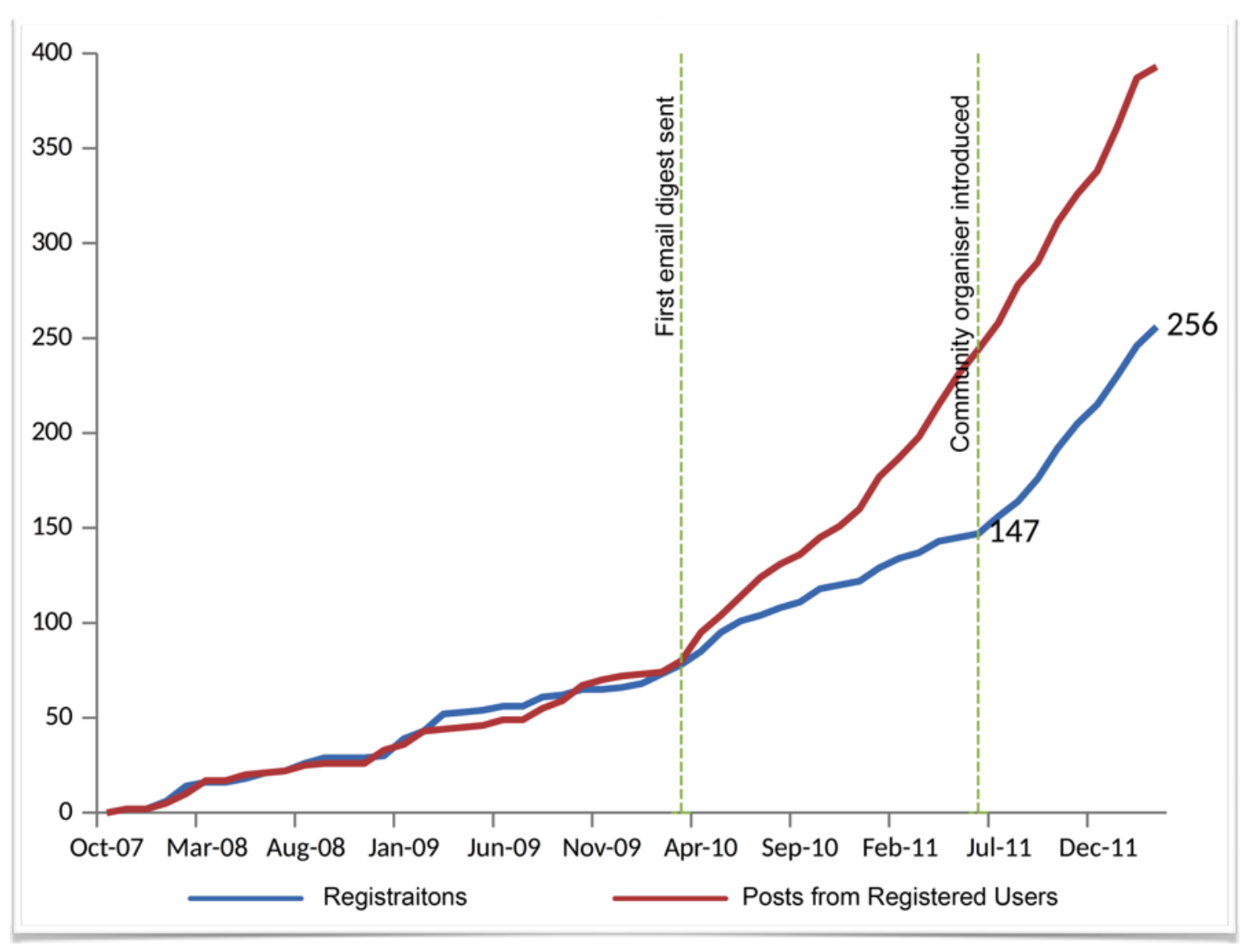

Figure 9: Registrations and registered users posting growth.

We describe community organisers as people who are motivated to volunteer time for local community interests and this often involves motivating others to help with this work. Community organisers are typically leaders or key members of community organisations and groups. While we have acted as facilitators to seed early use, community organisers have a more integral role as facilitators within the communications fabric. 


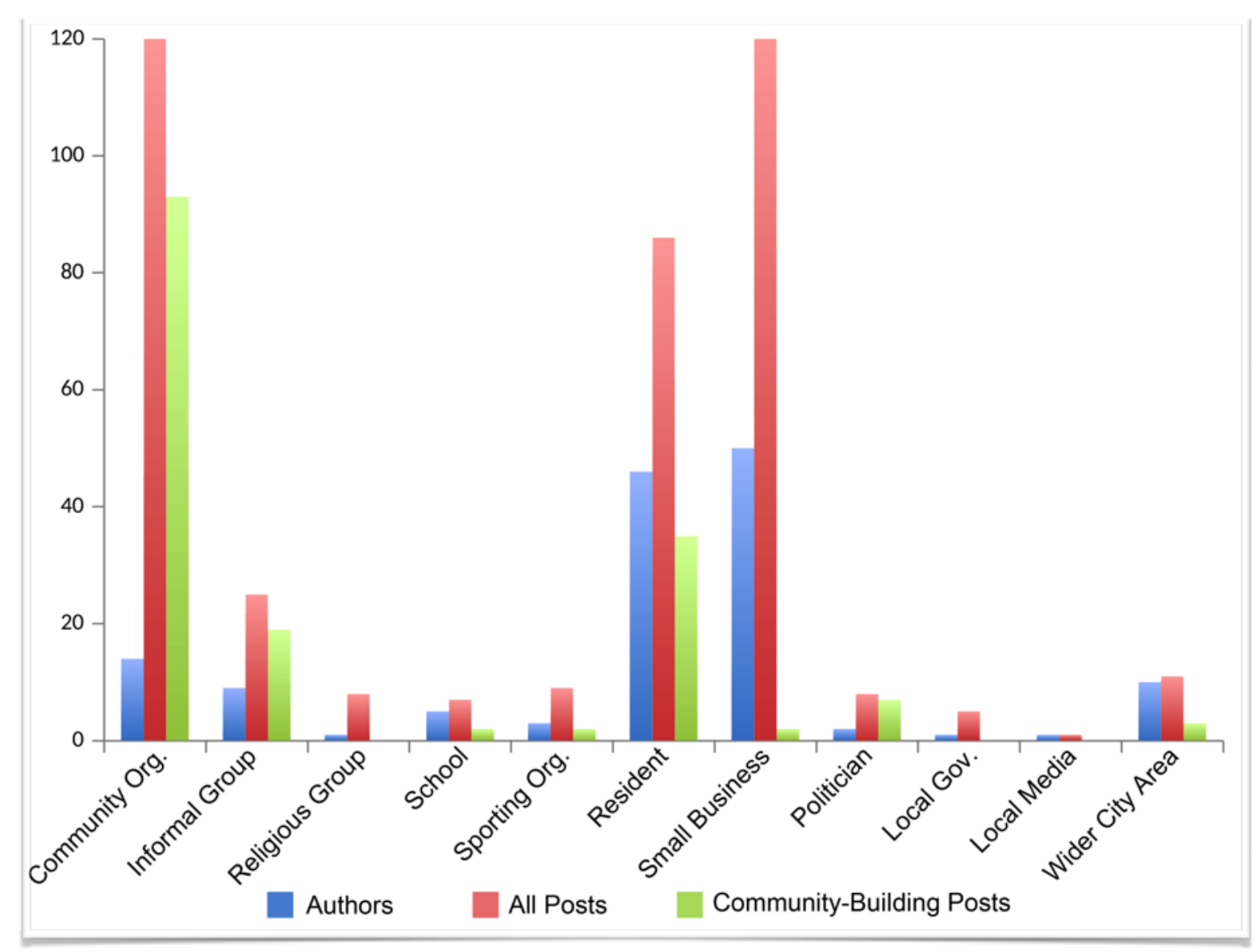

Figure 10: Number of author types, posts per author type, and community-building posts per author type.

\section{The Role of the Community Organisers in Growing Community Building Posts}

Community organisers have influenced an increase in community-building communications being posted to the noticeboard. The large majority of authors are residents and small business and these groups together have produced a high number of posts. By contrast, a much smaller number of community organisations have produced a relatively high number of posts, and in particular, community-building posts (figure 10).

Many of these community-building posts were made by a community organisation established shortly after the introduction of the email digest. The high rate of communitybuilding posts made by the new community organisation worked to seed community-building posts and prompt participation in these kinds of communications (figure 11). Nearly half of the community-building posts from the community association called for help to rebuild the locality after major city floods in January 2011 (44\% from January 2011 to March 2012). Bellbowrie and Moggill were amongst the worst flood affected areas and this crisis presented a very direct need for the community to organise short-term help and fundraise for longerterm rebuilding. While a good proportion of community-building posts from the community association were about the floods, only a very small proportion of community-building posts from other community members were about the floods (.07\% from January 2011 to March 2012). This points to the role of community organisers in networking these kinds of communications, but this data also illustrates the strong influence of the community 
organisation, rather than the floods crisis, to increase the rate of community-building communications from the community

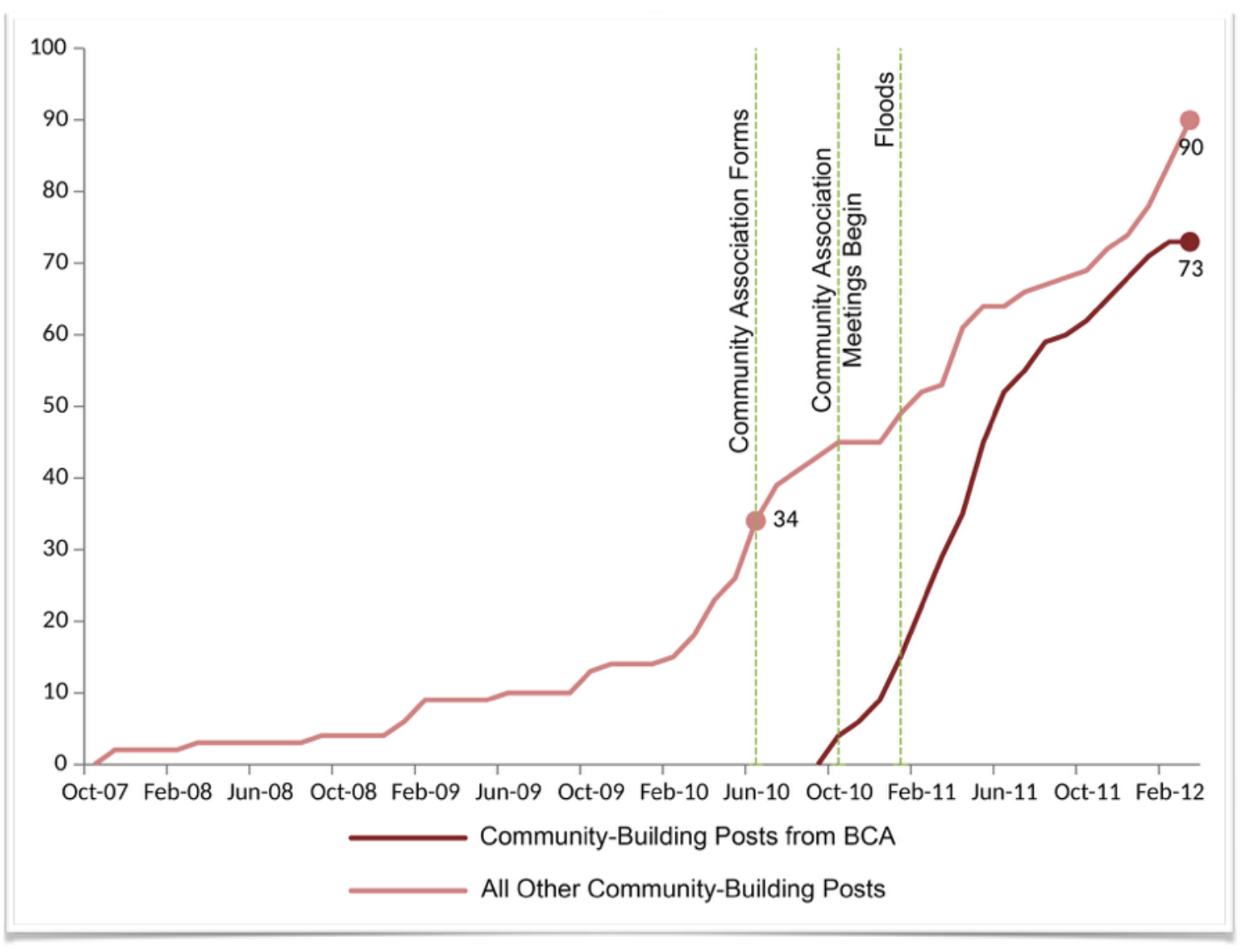

Figure 11: Growth in community-building posts after the formation of the local community association.

The lessons learnt about the mechanisms for growth of participation are:

- The role of a facilitator in seeding use in a local community communications network is critical to initiating contributions from community members.

- Clear indication that communications are being seen in local communications network motivates community members to make contributions.

- The influence of community organisers strengthens the community building aspects of a local communications network.

\section{The Challenges of sustaining Shared Communications}

People have recurring interest in viewing community-building posts. At the scale of this local community, communications about community-building ideas have trickled through the local community and have needed a time frame of years to gather commitment and momentum. Continued visibility of these ideas in the shared local communications fabric is needed to grow participation in community activity that progresses an idea into realisation. 
We observed the key challenges of sustaining shared communications are to:

- maintain visibility of community-building communications amongst other kinds of communication (e.g. momentary and ephemeral communications), and

- negotiate the control of local communications.

\section{The Challenge of Maintaining Visibility of Community-Building Communications}

Highly subscribed social media are known to be active and are constantly visible to their subscribers with access designed for 'always on' Internet technologies and market leading mobile devices. This clearly perceived visibility presents a great deal of usefulness for motivating participation. Facebook has been a highly subscribed and visible communication channel for the locality, notably since the formation of the new community association (around mid 2010) and the work needed to rebuild after the floods in January 2011.

The pace of communications on these Facebook groups has been extremely fast with as many as fifty or more posts being made on many days. Our findings show that community-building communications require long time frames to gather community interest. This is a point for further analysis, however, much social media offers little support for longer conversations that go beyond short-term organisation and other in-the-moment and ephemeral communications. Old posts are either no longer available or very hard to find. Our findings suggest that future design for local communications would benefit from accommodating visibility of both short-term communications and long-term communications.

\section{The Challenge of Negotiating Control of Shared Communications}

We observed the work of negotiating control and moderation of a shared communications platforms can quickly become political and overwhelming. Issues of negotiating control and moderation include relevance of contributions to the interest of the communication channel and moderation of political and other opinions. Despite wide community participation, an overload of negotiation issues can cause facilitators to close down the communication channel..

Negotiating control and moderation of local communications is tied to community organisers and the interests that motivated their work in the community. As an example, the founding interest of the community association was to challenge the monopoly owners of local commercial land. However the immediate need for communication around the flood crisis inspired rapid growth in communications from local community members on the association Facebook group, and the discussions became removed from the motivating interests of the association. This growth in participation and in competing opinions overwhelmed the management committee and the decision to control communications around the interests of the association was made. While the association Facebook group remains, posts are now limited to committee members only.

In reaction to the control imposed by the management committee on this communication channel, a new community Facebook group was created. In a move away from the formal and legal structure of the community association, this community Facebook group had an ad hoc structure. The main interest of the founders of this group was to allow open community 
discussion in a manner that would evolve interests and ideas free from the constraints of a leading viewpoint or aim. Although their aims were to share interests, the enthusiastic participation from members of the association Facebook group immediately transferred to the community Facebook group and the creators and administrators were again quickly overwhelmed by the work of negotiating control and moderation. Administrators were forced to moderate and respond to bouts of negativity in a bid to progress constructive communitybuilding communications. With this pressure to negotiate control and moderation, the work of facilitating this shared communications channel quickly become messy and political, and the decision to close the group was made within months.

Through the noticeboard application, we have not received anywhere near the pace of posts or the pressures to moderate as the association and community Facebook groups. The noticeboard metaphor places personalities in the background of the communications and while this may hinder personal connection, the distance provides a platform to share communications without the pressure to work out affiliations. These observations suggest that while we found the role of the facilitator is integral to growth in community member participation in a local communications network, design that gives greater emphasis to making local community communications public and accessible, and places less importance to networking individual identities is needed.

\section{Conclusions}

In conclusion, we found there is long-term community interest in community-building ideas and topics for discussion as evidenced by continued views of these posts. Communitybuilding posts have trickled through local communications channels over years as a means to gather interest and participation. The role of facilitators has been important to seeding use, broadening participation, and influencing the growth of community building posts. In addition, mechanisms (e.g. the email digest) that make communications visible within a networked group of members encourage recurrence of participation.

Visibility of local communications has been well supported by Facebook, however longerterm communications are lost in the fast paced nature of this network. Issues of control and moderation can overwhelm facilitators of shared communication channels and directly impact community member access to local communication channels. We suggest that future design accommodate visibility of both short and long term communications, and provide an accessible place to make communications public (with less concern for making connections between individuals).

The findings reported could not have been made in a matter of weeks or months because events such as floods, formations of clubs and associations, and other changes in community infrastructure that impact the local communications fabric do not happen in short timeframes. The realisation that local community-building happens in a time frame of years is key, and our understanding of design for local communications is grounded in this important characteristic of community building. The contribution of this study is the lessons learnt and realised over a long-term study of a local communications network, and the design directions suggested for future work in this area. 
Our approach to researching design for participation in local communications has been exploratory, taken years, and included anyone in the community that has shown any level of interest. Our display survived the summer heat of the Moggill General Store with little attention or pampering from anyone, and a lot of full speed, excited and grimy-handed scribbling from school kids. The process of bringing together the data has been messy; crunching years of logging data into the shape of a few graphs, an attempt at putting a feedback book with the display (only to gather random comments about who smells like what), chats with shop owners and school teachers and others in the community, workshops that turned out to be unsuited to collecting meaningful data for this kind of study, long interviews full of a wealth of knowledge about community organising, and unintentionally gathering a community collection of penis Scribbles. It would be impossible to prescribe how to replicate this study. However, the work has been very honest in terms of the realities of gathering broad local community member participation and sustaining this through times when there is no community crisis that is driving the need to gather as much help as possible. We have not ignored the realities of suburban communities and for this reason we believe the lessons learnt and the design suggestions made from our work are relevant to future work in other suburban communities.

\section{ACKNOWLEDGMENTS}

We thank the people who have tried out our prototypes in our communities and the Australian Research Council for funding of Discovery Grant DP DP1111999 - Cooperation and Reciprocity at the Local Scale Enabled by Social and Mobile Technologies.

\section{References}

Alt, F., Kubitza, T. , Bial, D. , Zaidan, F. , Ortel, M., Zurmaar, B., Lewen, T., Schmidt, A. (2011). Digifieds: insights into deploying digital public notice areas in the wild. Paper presented at the MUM '11, Beijing, China.

Ananny, M., Strohecker, C., Biddick, K. (2004). Shifting Scales on Common Ground: Developing Personal Expressions and Public Opinions. International Journal of Continuing Engineering Education and Life-Long Learning, 14(6), 484-505.

Australian Bureau of Statistics. (2013). National Regional Profile: Bellbowrie - Moggill (Statistical Area Level 2). 2015. Retrieved from http://www.abs.gov.au/AUSSTATS/ abs@nrp.nsf/Previousproducts/304021086Population/People12007-2011? opendocument \& tabname $=$ Summary $\&$ prodno $=304021086 \&$ issue $=2007-2011$

Blacksburg Government. (2012). Demographics. Retrieved from http://www.blacksburg.gov/ index.aspx?page $=221$

Brignull, H., Izadi, S., Fitzpatrick, G., Rogers, Y., Rodden, T. (2004, November 6-10). The Introduction of a Shared Interactive Surface into a Communal Space. Paper presented at the CSCW '04, Chicago, Illinois.

Brynskov, M., Dalsgaard, P., Ebsen, T., Fritsch, J., Halskov, K., Nielsen, R. (2009). Staging Urban Interactions with Media Facades. Paper presented at the INTERACT '09, Uppsala, Sweden. 
Carroll, J. M. (2005). The Blacksburg Electronic Village: A Study in Community Computing. In P. van den Besselaar \& S. Koizumi (Eds.), Digital Cities III (pp. 43-65). Berlin Heidelberg: Springer-Verlag.

Cederman-Haysom, T., Brereton, M. (2006). A participatory design agenda for ubiquitous computing : a case study in dental practice. Paper presented at the PDC '06, Trento, Italy.

Churchill, E., Nelson, L. (2007). Interactive Community Bulletin Boards as Conversational Hubs and Sites for Playful Visual Repartee. Paper presented at the HICSS-40 '07, Hawaii.

Churchill, E., Nelson, L., Denoue, L., Helfman, J., Murphy, P. (2004, August 1-4). Sharing Multimedia Content with Interactive Public Displays: A Case Study. Paper presented at the DIS '04, Cambridge, Massachusetts.

Crabtree, A., Benford, S., Greenhalgh, C., Tennent, P., Chalmers, M., Brown, B. (2006). Supporting Ethnographic Studies of Ubiquitous Computing in the Wild. Paper presented at the DIS '06, Pennsylvania, USA.

Farnham, S. D., McCarthy, J. F., Patel, Y., Ahuja, S., Norman, D., Hazlewood, W. R., Lind, J. (2009). Measuring the Impact of Third Place Attachment on the Adoption of a PlaceBased Community Technology. Paper presented at the CHI '09, Boston, MA, USA.

Gaver, B. (2002). Provocative Awareness. Computer Supported Cooperative Work, 11, 475-493.

Greenberg, S., Rounding, M. (2001). The Notification Collage: Posting Information to Public and Personal Displays. Paper presented at the CHI '01, Seattle, WA.

Heyer, C. (2008). Mobile Social Software. (Interaction Design PhD), University of Queensland, Brisbane.

Heyer, C., \& Brereton, M. (2008). Reflective Agile Iterative Design. Paper presented at the SIMTech Workshop on Social Interaction with Mundane Technologies, Cambridge, UK.

Heyer, C., Brereton, M., Viller, S. (2008). Cross-channel mobile social software: an empirical study. Paper presented at the CHI '08, Florence, Italy.

Hutchinson, H., Mackay, W., Westerlund, B., Bederson, B., Druin, A., Plaisant, C. Beaudouin-Lafon, M., Conversy, S., Evans, H,. Heiko, H., Roussel, N., Eiderback, B., Lindquist, S., Sundblad, Y. (2003). Technology Probes: Inspiring Design for and with Families. Paper presented at the CHI '03, Florida, USA.

Jacucci, G., Morrison, A., Richard, G., Kleimola, J., Peltonen, P., Parisi, L., Laitinen, T. (2010). Worlds of Information: Designing for Engagement at a Public Multi-touch Display. Paper presented at the CHI '11, Atlanta, GA, USA.

Kray, C. , Cheverst, K., Fitton, D., Sas, C., Patterson, J., Rouncefield, M., Stahl, C. (2006, September 12-15). Sharing Control of Dispersed Situated Displays between Nomadic and Residential Users. Paper presented at the Mobile HCI '06, Helsinki, Finland.

Leong, T., Brynskov, M. (2009). Co2nfession: Engaging with values through urban conversations. Paper presented at the OZCHI '09, Melbourne, Australia. 
Otis, N., Johanson, G. (2004, April 14-15). Community Building and Information and Communications Technologies: Current Knowledge. Paper presented at the Australian Electronic Governance Conference, Melbourne, Australia.

Peltonen, P., Kurvinen, E. , Salovaara, A. , Jacucci, G., Ilmonen, T., Evans, J., Oulasvirta, A., Saarikko, P. (2008, April 5-10). "It's Mine, Don't Touch!": Interactions at a Large Multi-Touch Display in a City Centre. Paper presented at the CHI '08, Florence, Italy.

Peltonen, P., Salovaara, A., Jacucci, G., Ilmonen, T. , Ardito, C. , Saarikko, P., Batra, V. (2007, December 12-14). Extending Large-Scale Event Participation with UserCreated Mobile Media on a Public Display. Paper presented at the MUM '07, Oulu, Finland.

Redhead, F., Brereton, M. (2006). A Qualitative Analysis of Local Community Communications. Paper presented at the OZCHI '06, Sydney, Australia.

Redhead, F., Brereton, M. (2008, Oct 1-4). Getting to the Nub of Neighbourhood Interaction. Paper presented at the PDC '08, Bloomington, Indiana.

Redhead, F., Brereton, M. (2009). Designing Interaction for Local Communications: An Urban Screen Study. Lecture Notes in Computer Science, 5727, 457-460.

Redhead, F., Brereton, M. (2010). Iterative Design within a Local Communication Fabric. Paper presented at the OZCHI '10, Brisbane, Australia.

Redhead, F., Brereton, M. (2012). Growing Local Participation Through Long Term Design. Paper presented at the PIN-C '12, Melbourne, Australia.

Schuler, D. (2005). The Seattle Community Network: Anomaly or Replicable Model? In P. van den Besselaar \& S. Koizumi (Eds.), Digital Cities III (pp. 17-42). Berlin Heidelberg: Springer-Verlag.

Seattle Government. (2011). Seattle's Population \& Demographics. 2015, Retrieved from http://www.seattle.gov/DPD/cityplanning/populationdemographics/aboutseattle/ population/default.htm

Stoecker, R.. (2004, June 18). Is Community Informatics Good for Communities? Questions Confronting an Emerging Field. Paper presented at the Networking Communities Forum, Melbourne, Australia.

Taylor, N., Cheverst, K., Fitton, D., Race, N., Rouncefield, M., Graham, C. (2007). Probing Communities: Study of a Village Photo Display. Paper presented at the OZCHI '07, Adelaide, Australia. 